\title{
A mobile ecology of resources for COVID-19 learning
}

\author{
Vickel Narayan, Thomas Cochrane, Neil Cowie, Meredith Hinze, James Birt ${ }^{7}$, Chris \\ Deneen $^{2}$, Paul Goldacre ${ }^{6}$, Lisa Ransom ${ }^{4}$, David Sinfield ${ }^{4}$, Tom Worthington ${ }^{5}$
}

${ }^{1}$ University of Sydney, University of Melbourne, Okayama University, University of Melbourne, Bond University, University of Melbourne, The University of Queensland, Auckland University of Technology, Auckland University of Technology, Australian National University

\begin{abstract}
Mobile devices and a vast array of accompanying applications offer significant affordances to create, consume, share, collaborate and communicate - affordances that could be easily leveraged to facilitate meaningful learning. A positive disruption arising from COVID-19 that aligns with the affordances of mobile learning is the uncoupling of time and space in the learning process. Traditionally formal learning is a process that is predominately viewed as an experience that is 'timetabled' - scheduled to eventuate at a 'place'-lecture or a tutorial (or similar) in a room or lecture theatre. In this concise paper, an ecology of resources is discussed along with guiding principles for designing and facilitating uncoupled authentic and student-determined learning post the emergency remote teaching phase.
\end{abstract}

Keywords: Mobile learning, ecology of resources, COVID-19, collaborative learning

\section{Introduction}

Educators around the world have had to switch to emergency remote teaching in a matter of days, for some it happened overnight (Bozkurt et al., 2020). While students have always met the educators in their space that is equipped and set up for learning and teaching (e.g., computer labs, simulation rooms, tutorial spaces and lecture rooms), COVID-19 meant the educators now had to venture into spaces students dwelt in to facilitate learning, as they learnt from home. More so, a lot of what students did and how they learnt depended on the devices they owned, resources they had access to and internet connectivity. To ensure access and an equitable learning experience many universities created and supported learning using a virtual private network (VPN), in particular, for students in China. Many campuses closed completely, and staff and students were requested to teach and learn from home. The switch to emergency remote teaching made it clear, even to those that were already working online, that there were going to be an enormous number of challenges (Crawford et al., 2020). These challenges included the need for teachers to rethink their teaching approach, course design, assessment, strategies for facilitating learning (learning tasks and activities) and access to content, which would normally be delivered in a physical space through a lecture. In addition, for many, working at home would have been a challenge in itself with issues of Wi-Fi connectivity, privacy and the disruption caused by the blurring of work and home environments.

The ASCILITE Mobile Learning SIG established in 2016 consists of a group of teacher-researchers specialising in mobile technology who meet online to discuss and research the opportunities that mobile learning offers (Cochrane \& Narayan, 2018). The SIG responded to the COVID-19 situation by creating a number of collaborative documents over a six month period with the aim of supporting staff and students in higher education. The SIG has more than 70 members based in several countries, including New Zealand, Australia, the UK and Japan, who bring an international perspective to the affordances and limitations of mobile learning. One of these documents is a cocurated selection of mobile tools that can be used to respond to the challenges of emergency remote teaching. This paper will describe how this Ecology of Resources (EoR) (Luckin, 2008) was created, list the main tools that are included, and make a number of recommendations in terms of implementing mobile learning.

\section{Literature review}

Over the last decade, the ownership of mobile devices and, in particular, smart mobile devices (phones and tablets) and accessories (VR headsets, smartwatch, etc.) have increased at a phenomenal rate (Pew Research Centre, 2019). A high percentage of students entering higher education in Australia and New Zealand own these devices, almost comparable to the rate of ownership of laptops (Beetham, Newman, \& Knight, 2019). Mobile devices and the plethora of accompanying applications offer significant affordances to create, consume, share, collaborate, cocreate and communicate - affordances that could be easily leveraged to facilitate meaningful learning (Narayan, 
Herrington, \& Cochrane, 2019). A positive disruption arising from COVID-19 that deserves further investigation but aligns with mobile learning is the uncoupling of time and space in the learning process (Sharples, 2015). Formal learning is a process that is predominately viewed as an experience that is 'timetabled' - scheduled to eventuate at a 'place'-lecture or a tutorial (or similar) in a room or lecture theatre.

Uncoupling the two constant variables that have dominated learning and teaching requires a significant rethink and understanding of where and how learning occurs (Beetham \& Sharpe, 2020). To begin, it implies that learning can occur at any time and any place. Perhaps a critical question to ask at this juncture is at what times and what places/spaces. Central to this argument is the fact that educational institutions no longer have control over this process - for a change, students do. The contexts where learning and teaching occurred changed overnight during the emergency remote online teaching phase - off-campus and into the informal spaces students dwell inincluding the cultural, social, digital and temporal spaces (Bachmair \& Pachler, 2014). This change significantly impacts the type of content that is traditionally created by the teacher for the students, the learning tasks and activities, assessment and learning scaffolds. Agreeing with this, Beetham, Newmen and Knight (2019) state that when digital technologies are effectively integrated into the design of the course and facilitation processes, it enables independent learning and allows the students 'to fit learning into their life more easily' (p. 13). With increased learner autonomy in the process, the students are able to drive and determine their own learning path and processes (Hase \&Kenyon, 2000), find true-collaborators to scaffold their learning and learn in authentic contexts (Narayan, Herrington \& Cochrane, 2019).

Another significant rethink that is required when space and time are uncoupled is the role of the learning environment (Holland, 2019). A consistent ingredient ever-present in higher education is the use of a learning management system (LMS). While in a formal learning environment, effective use of an LMS may complement learning, Luckin (2008) suggests an alternative learner-centric ecology of resources model (EoR) to scaffold learning in student spaces. Luckin espouses an EoR as a collection of people (knowledgeable others), resources (technology, books, digital resources, the library, etc.) and environment (cultural, social, digital and temporal), where the learner's interactions between the three elements create a context for the student to create new meaning and knowledge. An EoR is not a static collection of people, resources and environment rather an on- demand ecology that the learner might create to inform the learning process - it is dynamic, collaborative, social and changes according to the needs for the learner. The following section discusses how the mobile EoR was created as part of the Mobile learning SIG.

\section{Methodology}

The idea for a teaching and learning resource comprised of research-informed practical strategies to leverage the unique affordances of mobile devices to respond to the enormity of challenges to upskilling academic staff in their rapid shift to online learning drew upon several activities that the SIG engaged with over a number of weeks through their weekly webinar series. The weekly webinars discussed a range of emerging current topics, twominute tips, and presentations of best practice from invited guests. Some of the resources that the SIG drew upon for discussions included recently published practical guides for Web 2 (Bower \& Torrington, 2020), facilitating open book exams (Deneen, 2020), designing authentic mobile learning (Cochrane, 2020), JISC reports (Newman, Beetham, \& Knight, 2019), and a guest presentation calling for capitalising on opportunity within chaos (Blaschke, 2020). The SIG chose Padlet as a rapid development platform to co-create a mobile learning ecology of resources guide. Over two weeks the SIG collaborated to create and curate this guide both synchronously via Zoom, and asynchronously and involved critical SIG member reflections on practice and on their research in mobile learning.

As summarised in Figure 1 the co-created Padlet resource was structured around several key themes brainstormed by the SIG members. The Padlet drew upon the SIG expertise in various discipline contexts and knowledge of the literature, illustrated by a range of best practice ideas and resources collated under these central themes. 


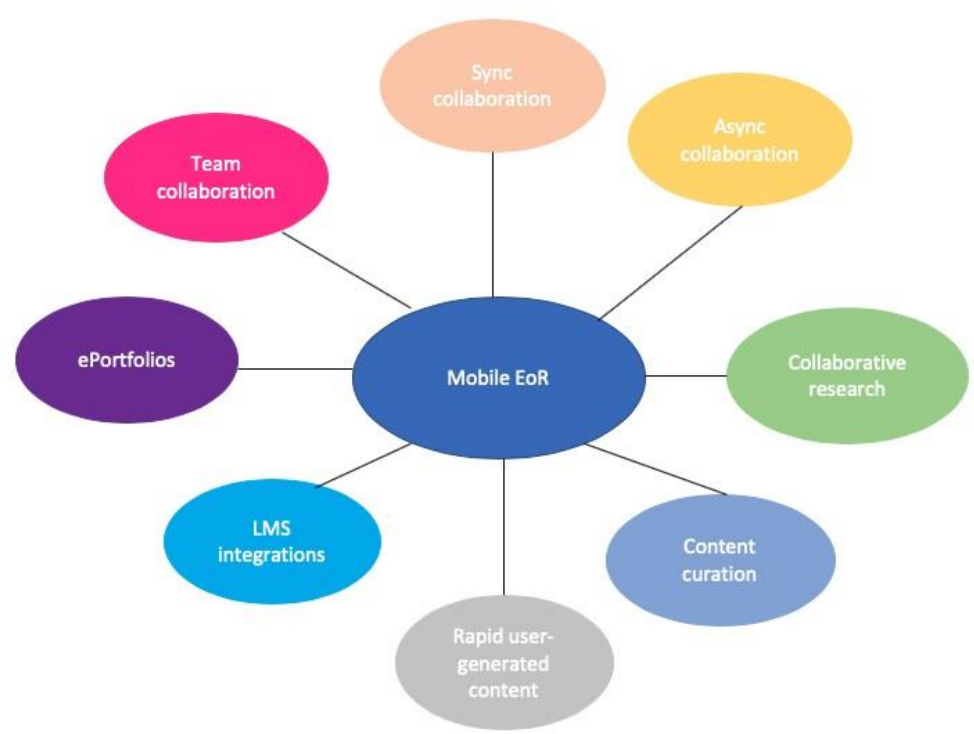

Figure 1: Summary of key themes for A Mobile Ecology of Resources (EoR) during the COVID-19 crisis

The key themes were structured around the authentic use of mobile learning, focusing upon the learning and teaching strategies enabled by the unique affordances of mobile devices, with a focus upon moving beyond substitution of pedagogical practice on a mobile platform to redefining the pedagogical possibilities afforded by mobile learning (Puentedura, 2010). The themes and tools are discussed in the section below.

\section{Discussion}

Socio-cultural pedagogies dating back to Dewey (1916) have advocated collaboration, communication and cocreation as effective pedagogical strategies. It placed students at the centre of the learning process and as main agents in creating knowledge and meaning through interaction in multiple contexts. Pre-COVID-19, there was perhaps no catalyst of this magnitude in academia to meet the students in their world. COVID-19 imposed significant limitations in a very short timeframe and in many instances created knowledge gaps that simply could not be attended to. The mobile EoR created by the SIG members based on reflections on their teaching, expertise, support strategies and research highlights three elements critical for designing and facilitating learning using mobile devices in student spaces. (1) Collaboration at an individual, group and class level including the ability to connect with others beyond peers and teachers synchronously and asynchronously. (2) The ability to create, capture, co-create and curate content for use in the learning process and (3) easy access to critical information and content. Central to the three elements is the role of mobile devices, its affordances and the app (application) ecology that support different types of engagement and learner actions in informal contexts. The different affordances act as mediators for establishing and encouraging interactions in the EoR between people, resources and environment (Bachmair \& Pachler, 2014). Drawn from the Mobile EoR PADLET Table 1 provides an overview of three categories, mobile applications and how it may be implemented in learning and teaching during COVID-19.

Table 1: The EoR, affordances, tools and implementation

\begin{tabular}{|l|l|l|l|}
\hline Category & Affordances & Applications & Implementation \\
\hline Collaboration & $\begin{array}{l}\text { Team } \\
\text { collaboration }\end{array}$ & $\begin{array}{l}\text { Slack, MS Teams, } \\
\text { Trello }\end{array}$ & $\begin{array}{l}\text { Establish a learner community. } \\
\text { Encourage students to share resources, ideas and } \\
\text { their work. } \\
\text { Create group learning tasks and projects. }\end{array}$ \\
\hline
\end{tabular}




\begin{tabular}{|c|c|c|c|}
\hline & $\begin{array}{l}\text { Synchronous } \\
\text { collaboration }\end{array}$ & $\begin{array}{l}\text { Zoom and other video } \\
\text { live streaming tools, } \\
\text { Teams chat, } \\
\text { Blackboard } \\
\text { Collaborate }\end{array}$ & $\begin{array}{l}\text { Utilise the time to create social presence embedded } \\
\text { in collaborative learning principles. } \\
\text { Provide scaffolding and support. }\end{array}$ \\
\hline & $\begin{array}{l}\text { Asynchronous } \\
\text { collaboration }\end{array}$ & $\begin{array}{l}\text { Twitter, WhatsApp, } \\
\text { Yammer, Flipgrid, } \\
\text { Padlet }\end{array}$ & $\begin{array}{l}\text { Establish a learner community. } \\
\text { Create learning tasks that enable communication } \\
\text { and co-creation between students and } \\
\text { knowledgeable others. } \\
\text { Create tasks that students can complete at their own } \\
\text { time and pace. } \\
\text { Encourage students to create organic groups for } \\
\text { social and learning purposes. }\end{array}$ \\
\hline & $\begin{array}{l}\text { Research } \\
\text { collaboration }\end{array}$ & $\begin{array}{l}\text { ResearchGate, } \\
\text { Mendeley, } \\
\text { academia.edu }\end{array}$ & $\begin{array}{l}\text { Create opportunities to share knowledge and } \\
\text { resources that might benefit others in class. }\end{array}$ \\
\hline \multirow[t]{3}{*}{$\begin{array}{l}\text { Create, curate and } \\
\text { capture }\end{array}$} & ePortfolio Apps & $\begin{array}{l}\text { Behance, WordPress, } \\
\text { PebblePad, Padlet, } \\
\text { LinkedIn }\end{array}$ & $\begin{array}{l}\text { Embed an ongoing semester-long assessment in the } \\
\text { course. } \\
\text { Encourage students to curate data and content as } \\
\text { part of their learning. } \\
\text { Help students establish a professional online } \\
\text { identity. } \\
\text { Facilitate reflective learning. }\end{array}$ \\
\hline & $\begin{array}{l}\text { Rapid user- } \\
\text { generated } \\
\text { content }\end{array}$ & $\begin{array}{l}\text { Video mobile apps, } \\
\text { Adobe Creative Mobile } \\
\text { Suite, Filmic Pro, } \\
\text { Audio recording apps }\end{array}$ & $\begin{array}{l}\text { Allow students to experiment with their knowledge } \\
\text { in real-world contexts (or equivalent). } \\
\text { Encourage students to capture multimedia content } \\
\text { as part of their learning journey. } \\
\text { Create tasks that require students to co- create } \\
\text { content and meaning together. }\end{array}$ \\
\hline & Content curation & $\begin{array}{l}\text { RSS - Flipboard, code } \\
\text { sharing - GitHub, } \\
\text { simple web content - } \\
\text { Google Sites, Padlet }\end{array}$ & $\begin{array}{l}\text { Integrate open educational resources in your } \\
\text { teaching. } \\
\text { Encourage students to share and collect learning } \\
\text { resources for the web. } \\
\text { Encourage open learning - knowledge is } \\
\text { everywhere, it is a matter of where and how you } \\
\text { seek it. } \\
\text { Encourage tagging for resources at a class level. }\end{array}$ \\
\hline $\begin{array}{l}\text { Access to content } \\
\text { and information }\end{array}$ & LMS Interaction & $\begin{array}{l}\text { LMS mobile apps, } \\
\text { Quitch, polling apps, } \\
\text { quiz apps }\end{array}$ & $\begin{array}{l}\text { Provide easy access to information and learning } \\
\text { resources. } \\
\text { Create formative assessments. } \\
\text { Provide timely, supportive and constructive } \\
\text { feedback. }\end{array}$ \\
\hline
\end{tabular}




\section{ASCILITE 2020 \\ ASCILTE's First Virtual Conference}

\section{Conclusions}

This concise paper provides a conceptual framework and guidance for implementing mobile learning that is informed by research and reflections on teaching practice from members of the ASCILITE Mobile SIG. COVID-19- 19 took from academia elements that were prized and had been refined over many years- the affordances of being on campus. It proposed a new challenge to teachers, for some almost overnight, to venture into uncharted territory going beyond physical institutional barriers and into the student world. It created serious adversities for teachers and students alike, but it also created an unprecedented opportunity to look at learning from a student's perspective and from the world they live in. For the SIG, it provided an opportunity to understand and analyse in a very short time frame strategies for using the one device the students have with them constantly that can be utilized for learning and teaching. Not just the device but also investigate the different contexts the learners live and dwell in and how it could be used for facilitating authentic and learnerdetermined learning experiences. As a result, the mobile ecology of resources for teaching during COVID-19 is provided (Figure 1) along with guiding principles (Table 1).

\section{Limitations and implications}

The paper discusses a small number of mobile applications and affordances as an ecology of resources that could be used for COVID-19 learning and teaching. It provides a snapshot of some of the emergent mobile pedagogies and tools during the early-mid (March-August) COVID-19 phase that are still evolving at a rapid rate.

\section{References}

Bachmair, B., \& Pachler, N. (2014). A cultural ecological frame for mobility and learning. In D. Meister, T. Hug, \& N. Friesen (Eds.), Educational media ecologies: International perspectives. (Vol. Special Issue of Medien Paedagogik, pp. 53-74). Retrieved from http://www.medienpaed.com/globalassets/medienpaed/24/bachmair_pachler1409.pdf

Beetham, H., Newman, T., \& Knight, S. (2019). Digital experience insights survey 2018: findings from Australian and New Zealand university students. Bristol, UK: JISC. Retrieved from http://repository.jisc.ac.uk/7202/1/digital-experience-insights-survey-anz-2018.pdf

Beetham, H., \& Sharpe, R. (2020). Rethinking Pedagogy for a Digital Age. Oxon, London: Routledge.

Blaschke, L. M. (2020). Transitioning to online: Capitalizing on opportunity within chaos We've made it through the emergency remote teaching phase. What next? Retrieved from https://tinyurl.com/y5aw4xky

Bower, M., \& Torrington, J. (2020, 29 April). Typology of Free Web-based Learning Technologies (2020). Retrieved from https://library.educause.edu/resources/2020/4/typology-of-free-web-based-learningtechnologies

Bozkurt, A., Jung, I., Xiao, J., Vladimirschi, V., Schuwer, R., Egorov, G., ... Paskevicius, M. (2020). A global outlook to the interruption of education due to COVID-19 pandemic: Navigating in a time of uncertainty and crisis. Asian Journal of Distance Education, 15(1), 1-126. doi: http://doi.org/10.5281/zenodo.3878572

Cochrane, T. (2020). Designing authentic mobile learning. Teaching and Learning Short Guides. Retrieved from https://tinyurl.com/y339kydn

Cochrane, T., \& Narayan, V. (2018). Nurturing collaborative networks of mobile learning researchers and practitioners. International Journal of Mobile and Blended Learning (IJMBL), 10(4), 73-92. doi:https://doi.org/10.4018/ijmbl.2018100105

Crawford, J., Butler-Henderson, K., Rudolph, J., \& Glowatz, M. (2020). COVID-19: Twenty countries' higher education intra-period digital pedagogy responses. Journal of Applied Teaching and Learning, 3(1). doi:https://doi.org/10.37074/jalt.2020.3.1.7

Deneen, C. (2020). Assessment considerations in moving from closed-book to open-book exams. Teaching and Learning Short Guides. Retrieved from https://tinyurl.com/y3ewfcjh

Dewey, J. (1916). Democracy and education. An introduction to the philosophy of education. New York: Free Press.

Hase, S., \& Kenyon, C. (2000). From andragogy to heutagogy. ultiBASE, 5(3). Retrieved from http://ultibase.rmit.edu.au/Articles/dec00/hase2.htm

Holland, A. A. (2019). Effective principles of informal online learning design: A theory-building metasynthesis of qualitative research. Computers \& Education, 128(2019), 214-226. 
doi:https://doi.org/10.1016/j.compedu.2018.09.026

Luckin, R. (2008). The learner centric ecology of resources: A framework for using technology to scaffold learning. Computers \& Education, 50, 449-462. doi:https://doi.org/10.1016/j.compedu.2007.09.018

Narayan, V., Herrington, J., \& Cochrane, T. (2019). Design principles for heutagogical learning: Implementing student-determined learning with mobile and social media tools. Australasian Journal of Educational Technology, 35(3), 73-92. doi:https://doi.org/10.14742/ajet.3941

Pew Research Centre. (2019). Smartphone ownership in growing rapidly around the world, but not always equally. USA: Pew Research Centre. Retrieved from https://www.pewresearch.org/global/2019/02/05/smartphone-ownership-is-growing-rapidly-around- theworld-but-not-always-equally/

Puentedura, R. R. (2010). SMAR and TPACK: Intro to advanced practice. Retrieved 3 March, 2012. Retrieved from http://hippasus.com/resources/sweden2010/SAMR TPCK IntroToAdvancedPractice.pdf

Sharples, M. (2015). Making sense of context for mobile learning. In J. Traxler \& A. Kukulska-Hulme (Eds.), Mobile learning: The next generation (pp. 140-153). New York: Routledge. Retrieved from https://www.routledge.com/products/9780415658362

Narayan, V., Cochrane, T., Cowie, N., Hinze, M., Birt, J., Deneen, C., Goldacre, P., Ransom, L., Sinfield, D. \& Worthington, T. (2020). A mobile ecology of resources for Covid-19 learning. In S. Gregory, S. Warburton, \& M. Parkes (Eds.), ASCILITE's First Virtual Conference. Proceedings ASCILITE 2020 in Armidale (pp. 174-179). https://doi.org/10.14742/ascilite2020.0122

Note: All published papers are refereed, having undergone a double-blind peer-review process.

The author(s) assign a Creative Commons by attribution licence enabling others to distribute, remix, tweak, and build upon their work, even commercially, as long as credit is given to the author(s) for the original creation.

(c) Narayan, V., Cochrane, T., Cowie, N., Hinze, M., Birt, J., Deneen, C., Goldacre, P., Ransom, L., Sinfield, D. \& Worthington, T. (2020) 